VII Congresso Brasileiro de Informática na Educação (CBIE 2018)

Anais do XXIX Simpósio Brasileiro de Informática na Educação (SBIE 2018)

\title{
A Viagem: Um jogo para explorar o território Brasileiro
}

\author{
Fernanda Gabriela de Sousa Pires ${ }^{123}$, João da Silva Queroga ${ }^{12}$, Marcela Sávia \\ Picanço Pessoa $^{13}$, Rafaela Melo Ferreira ${ }^{12}$ \\ ${ }^{1}$ Escola Superior de Tecnologia (EST) - Universidade do Estado do Amazonas (UEA) \\ ${ }^{2}$ Laboratório de Tecnologias Educacionais (LabTEd) \\ ${ }^{3}$ Instituto de Computação (ICOMP) - Universidade Federal do Amazonas (UFAM) \\ Manaus - AM - Brasil \\ \{fpires, jdsq.lic, msppessoa, rmf.lic16\}@uea.edu.br
}

\begin{abstract}
This article relates the process of development of an adventure game designed for mobile, "A Viagem", which has the objective of proportioning to the player knowledge about Brazilian territory: political division (states and capitals), flags, coat of arms and more. The process of development was agile, followed by a round of own experimental educational software, with the aim of evaluating the application of the learning theory to the game's engineering. The theoretical substrate applied is exploratory, having its design based on Cognitive Theory of Multimedia Learning. The results of the applied evaluations were positive, in the measures of learning, software testing, and measures of engagement.
\end{abstract}

Resumo. Este artigo relata o processo de desenvolvimento de um jogo de aventura, para plataformas móveis, "A Viagem", cujo objetivo é proporcionar ao jogador conhecimentos sobre o território brasileiro: divisão política (Estados e suas Capitais), bandeiras, brasões, etc. $O$ processo de desenvolvimento foi ágil, seguido um ciclo de software educacional experimental próprio, com a finalidade de avaliar a aplicação da Teoria de Aprendizagem à engenharia do jogo. O substrato teórico de Aprendizagem empregado é ativo e exploratório, sendo seu design visual baseado na Teoria Cognitiva da Aprendizagem Multimídia. Os resultados das avaliações aplicadas foram positivos, nas medidas de aprendizagem, testes de software, $e$ medidas de engajamento.

\section{Introdução}

A compreensão da Geografia no ambiente escolar, pertinente à cartografia e ao espaço físico, reduz-se basicamente a tópicos de um livro didático. Oliveira (2008) afirma que a Geografia em sala de aula passa a ser uma matéria onde somente se faz necessário o uso da memória de curto prazo, sem que haja conexão com o ambiente, desvinculando qualquer experiência e desprivilegiando a construção do conhecimento; é impelida a trabalhar com recortes de seu objeto de estudo, o espaço geográfico.

Aqui trataremos da cartografia, que nos entrega esses recortes, e abraçamos as possibilidades de viagem, explorando o mapa político brasileiro e seus símbolos, apresentando a experiência e oportunidade de ligação com o espaço, em uma linguagem alternativa, destacando também a importância dos símbolos como brasões e bandeiras, que tem como função representar qualquer instituição ou sociedade, com a responsabilidade de carregar histórias e tradições. 
VII Congresso Brasileiro de Informática na Educação (CBIE 2018)

Anais do XXIX Simpósio Brasileiro de Informática na Educação (SBIE 2018)

A cartografia, embora rica nas representações espaciais, tem uma linguagem que os professores de Geografia ainda não dominam de maneira satisfatória. Assim, deixa de ser explorado e usado nas aulas como poderia ser. Inicia-se desta forma um ciclo vicioso, pois com a deficiência na formação do professor, o aluno não aprende os conteúdos cartográficos; logo depois, este aluno entra em uma faculdade e ou universidade que forma professores de Geografia e, novamente, esses conteúdos não são repassados (LUNKES \& Martins).

Hoje é possível desfrutar de recursos mais atrativos para a aprendizagem cartográfica simbólica. Com as tecnologias de informação e comunicação se tornando mais acessíveis, a sociedade vem se transformando, e nas escolas esse processo não é diferente. No entanto, no âmbito escolar, o professor passa a não ser mais a única opção de busca por conhecimento, um leque de alternativas pedagógicas vêm sendo aberto com o passar dos anos, de acordo com (Santos \& Chiapetti, 2011, p.167), "os professores do século XXI necessitam utilizar várias mídias a favor do seu fazer pedagógico e, assim, a favor dos seus alunos e da sociedade em geral”, que sugere linguagens alternativas de comunicação com os discentes.

Este artigo trata sobre o desenvolvimento do jogo educacional para plataforma mobile, “A Viagem”, desenvolvido na game engine Unity, abordando a localização dos estados através de capitais, bandeiras e brasões, de forma gamificada. Este artigo está dividido em sete seções, descrito desde o processo de construção e abordagens teóricas aos resultados dos testes de usabilidade e considerações finais.

\section{Trabalhos Relacionados}

Lemos, Junior, \& Campos Filho (2017) desenvolveram o jogo Esqueleto Mania, voltado para a aprendizagem de anatomia humana, com o objetivo de motivar os alunos por meio de recursos lúdicos e interativos. Mesmo levando em consideração a teoria de aprendizagem significativa, os autores adotaram uma metodologia mais divertida e estimulante para o desenvolvimento do jogo. Em cada fase do jogo, o usuário deve montar um quebra-cabeça relacionado ao sistema esquelético. Os resultados dos testes realizados mostraram satisfação do usuário e um bom nível de usabilidade.

Tendo como motivação a necessidade de inovações no processo de aprendizagem, Sousa, Nunes, \& Martinhago (2017) apresentam o jogo Universo do Saber, voltado para as disciplinas de português, matemática e inglês. Destinado para plataformas mobile, o jogo tem como público-alvo alunos do ensino fundamental. Para tornar o jogo o mais lúdico possível, o cenário principal representa o universo, e cada um dos 3 planetas remete a uma das disciplinas abordadas no jogo, além de possuir um sistema de pontuação.

Em Netto, da Silva, de Melo, \& da Costa (2016) é apresentado o jogo Geography History, um aplicativo desenvolvido no Android Studio, por meio da linguagem de programação Java. O jogo, voltado para plataformas Android, apresenta o mapa da América do Sul e suas respectivas divisões políticas. Ao clicar em um país o jogador receberá informações sobre ele, como: clima, vegetação, relevo, população e moeda. Tendo como público-alvo alunos do $6^{\circ}$ ao $9^{\circ}$ ano do ensino fundamental, o jogo pretende auxiliar no processo de aprendizagem na disciplina de Geografia. 
VII Congresso Brasileiro de Informática na Educação (CBIE 2018)

Anais do XXIX Simpósio Brasileiro de Informática na Educação (SBIE 2018)

\section{O jogo A Viagem}

O software A Viagem foi desenvolvido na engine de jogos Unity, versão 2017, programado na linguagem C\# (C-Sharp), no sistema operacional Windows 10, o software foi desenvolvido para plataformas Android, com exigência mínima de Target SDK para Android 4.4.2 e todos os elementos gráficos do jogo são produções próprias.

O jogo educacional “A Viagem”, que tem como principal objetivo auxiliar na aprendizagem do mapa político do Brasil, é um jogo de aventura, de classificação everyone, segundo a classificação ESRB. O público-alvo são crianças com idade superior a 11 anos, que, de acordo com o Ministério da Educação (MEC), é a idade ideal para as pessoas iniciando o sétimo ano do ensino fundamental, nível da educação básica brasileira onde se iniciam os conteúdos de cartografia.

Os conteúdos de Geografia abordados no jogo são de localização geográfica, divisão política brasileira, símbolos e bandeiras nacionais referenciadas às localidades, orientação espacial, leitura e interpretação de mapas e características específicas de cada estado/capital. Fornece ao jogador um guia que permite conhecer tais dados sem o auxílio de um especialista na área, com a facilidade de acesso. O jogador se põe como um dos protagonistas da história em uma exploração e busca resolver desafios.

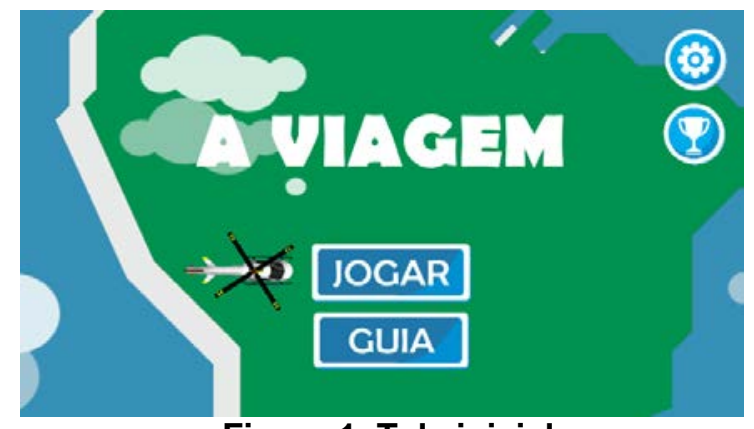

Figura 1. Tela inicial.

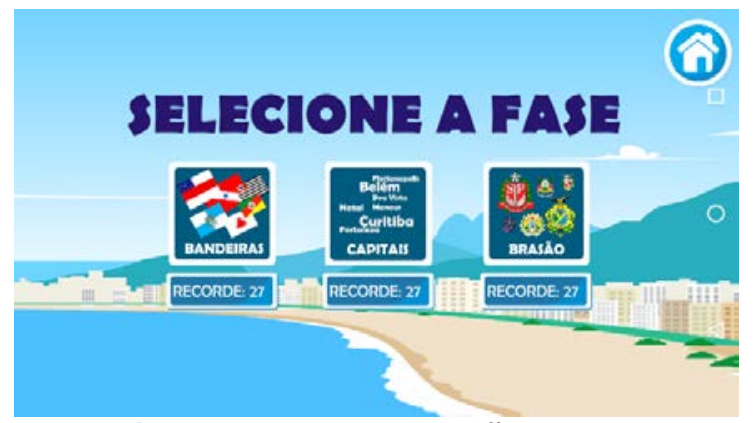

Figura 2. Tela de seleção de Fase.

\subsection{A construção de significados}

O público-alvo, de idade superior a 11 anos, segundo a teoria do desenvolvimento cognitivo de Piaget \& Duckworth (1970), apresenta avanços importantes ao lidar com realidades hipotéticas, não mais necessitando de uma referência concreta real. Segundo o teórico, a aprendizagem é modelada de acordo com o estágio de maturação da estrutura do pensamento, interação social e da experiência de forma ativa (Lefrançois, Magyar, \& Lomonaco, 2009). Com a finalidade de influenciar no desenvolvimento da compreensão da orientação espacial, da divisão dos estados brasileiros, o usuário recebe a missão de orientar o objeto, helicóptero, pelo mapa representativo da divisão política do Brasil. Na fase 1 (Figura 3), o objetivo é guiá-lo ao indicador do estado em que a bandeira pertence; na fase 2 (Figura 4), o objetivo é guiá-lo ao indicador do estado a qual pertence a capital indicada. 


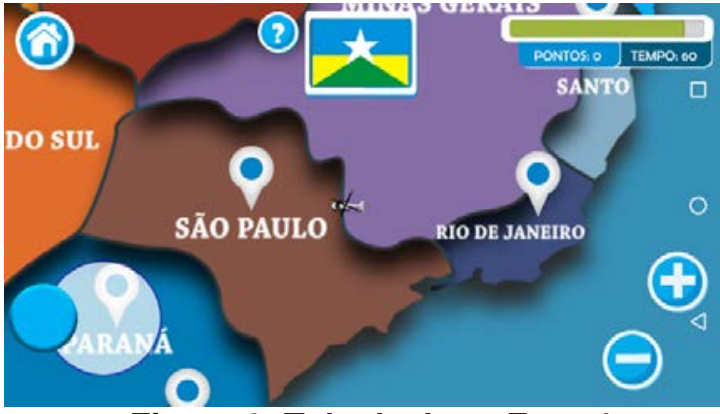

Figura 3. Tela de Jogo Fase 1.

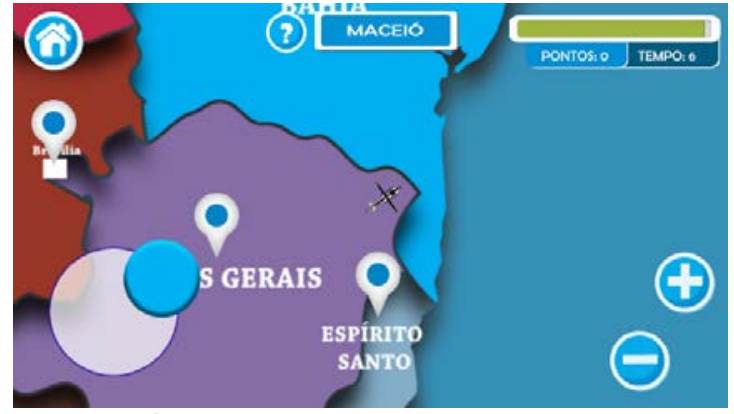

Figura 4. Tela de Jogo Fase 2.

Segundo Mayer (2002), as pessoas aprendem com mais facilidade quando existe uma associação entre as linguagens. Em sua teoria, Mayer afirma que em objetos multimídias, ao adicionar imagens e textos de forma que ambas as partes tenham a mesma finalidade, a possibilidade de ocorrer aprendizagem é maior. O jogo A viagem segue os princípios da teoria da carga cognitiva e aprendizagem multimídia, em basicamente todas as fases, quando é associado o nome do estado, o mapa, a bandeira ou o brasão.

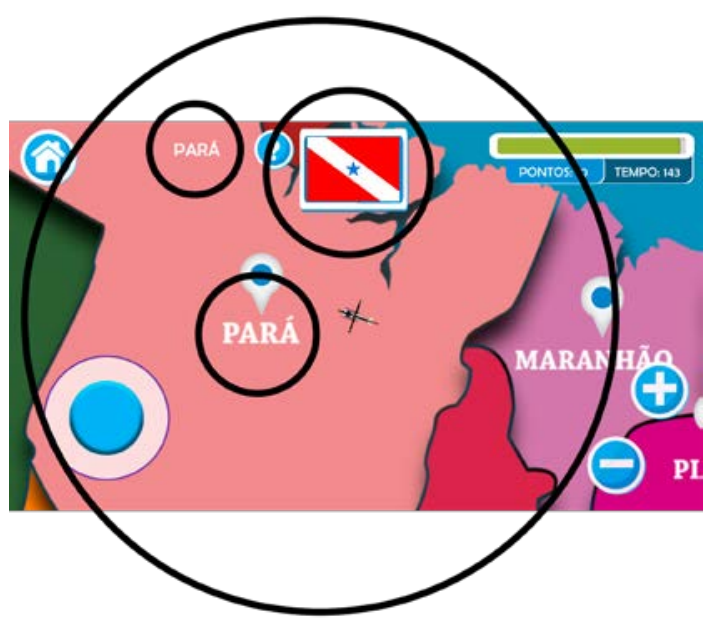

Figura 5. Teoria da Carga Cognitiva e Aprendizagem Multimídia.

Sendo um dos mercados que mais evolui, os games estão cada dia mais presentes no cotidiano das pessoas. Segundo Alves (2015), 97\% dos jovens jogam videogames e não tem intenção de parar de jogar, o que encoraja a criação de objetos de aprendizagem gamificados, como o jogo apresentado neste artigo.

\section{Processo de criação do jogo}

\subsection{A primeira ideia de Jogo - os requisitos a serem alcançados}

Requisito 1: (Guia) uma área onde o jogador possa estudar as informações de cada estado, quando achar necessário;

Requisito 2: (Configurações) tela para configurar aspectos do jogo, como som e nível de jogo;

Requisito 3: (Recordes) gravar os recordes de cada fase do jogo; 
VII Congresso Brasileiro de Informática na Educação (CBIE 2018)

Anais do XXIX Simpósio Brasileiro de Informática na Educação (SBIE 2018) jogo;

Requisito 4: (Redefinir) apagar todos os recordes e configurações salvas no

Requisito 5: (Selecionar a fase) escolher uma das fases para jogar;

Requisito 6: (Missão atual) mostrar o objetivo a ser cumprido pelo jogador, como bandeira ou capital;

Requisito 7: (Combustível) determina um tempo para a missão ser cumprida, com um decremento constante de combustível;

Requisito 8: (Acerto) quando o jogador passar o Avião sobre o pointer certo, incrementa um ponto no total de pontos e aumenta o combustível;

Requisito 9: (Erro) quando o jogador passar pelo pointer errado, decrementa uma porção do combustível;

Requisito 10: (Níveis de dificuldade) muda a velocidade de decremento do combustível dependendo do nível escolhido.

\subsection{Primeira versão para testes}

O jogo educacional A Viagem passou por um extenso processo de modificação e testes, para uma maior satisfação e conforto para o usuário. Como ideia inicial, o jogo estava sendo desenvolvido na engine Construct 2 para Web, que serviu de base para avaliação do projeto, proporcionando um desenvolvimento mais elaborado e com as alterações necessárias. A primeira jogabilidade utilizava as setas do teclado para movimentação do avião e o mouse para navegar pelas telas do jogo, as setas horizontais para girá-lo nos sentidos horário e anti-horário e as setas na vertical para controle de velocidade, como trata-se de um avião, deveria ficar em constante movimento para maior aproximação com mundo real.

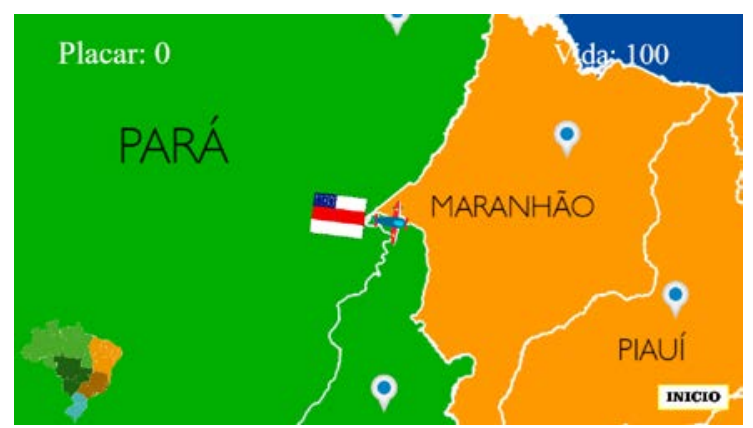

Figura 6. Jogabilidade inicial no Desktop.

Um dos principais questionamentos nesta primeira demonstração foi a combinação das cores, muito fortes e desagradáveis, que ocasionaram um desconforto no jogador, porque as cores influenciam diretamente nas emoções das pessoas e, determinada cor, pode produzir um efeito diferente para cada ocasião, podendo ir de um tom agradável que transmita calma, até um tom que transmita brutalidade ou tristeza (Heller, 2013). 
VII Congresso Brasileiro de Informática na Educação (CBIE 2018)

Anais do XXIX Simpósio Brasileiro de Informática na Educação (SBIE 2018)

\subsection{Alteração da Plataforma}

Levando em consideração o aumento da utilização de smartphones no Brasil nos últimos anos, realizou-se uma alteração de plataforma, de Desktop para Mobile, especificamente para a plataforma Android. Devido a diferença na interação HumanoComputador entre as plataformas, a interface precisou ser ajustada.

A primeira jogabilidade para a versão mobile buscava preservar o máximo da versão anterior, para computador, com o avião girando nos sentidos horário e antihorário, porém, com toques nas laterais da tela e botões nos cantos inferiores para aumentar e diminuir a velocidade.

Entretanto, esta não seria a jogabilidade ideal, de acordo com os testes realizados, pois a maior dificuldade das pessoas era justamente não reconhecer os controles do avião. Por isso, foi implementado um joystick no canto inferior esquerdo, passando os botões de velocidade para o inferior direito.

Um problema surgiu com esta implementação, a liberdade de movimentação seria maior, podendo ir para todas as direções possíveis e neste caso não representa a movimentação dos aviões no mundo real. Este imprevisto provocou a troca do principal elemento do jogo, que agora passa a ser um helicóptero, exatamente pela liberdade de movimentação, podendo ir para todas as direções sem muito esforço.

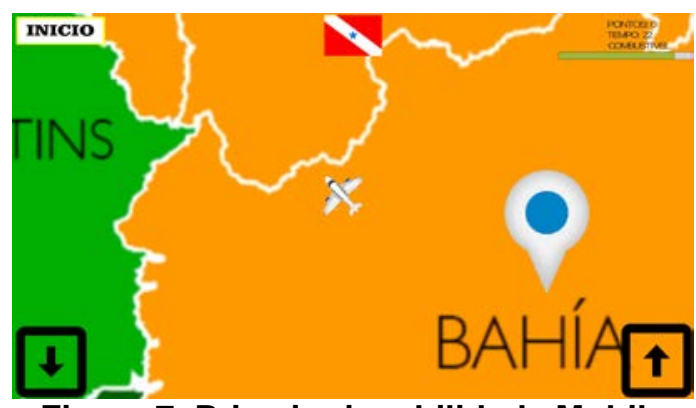

Figura 7. Primeira jogabilidade Mobile.

\subsection{Etapas do desenvolvimento}

Com todos os testes e atualizações realizados, foi definido o projeto para implementação, dividido em várias etapas, cujo objetivo seria incorporar o máximo de requisitos pré-definidos possíveis.

Etapa 1: (Criação da Mobilidade) É modelada e implementada a jogabilidade do helicóptero, com movimentação por joystick no canto inferior esquerdo, e modificação da velocidade através de botões no canto inferior direito, fazendo com que a câmera possa segui-lo;

Etapa 2: (Criando o ambiente) Nesta etapa é incorporado um mapa para que o helicóptero possa se locomover sobre ele, adicionando barreiras nas laterais impedindo que saia do mapa; 
VII Congresso Brasileiro de Informática na Educação (CBIE 2018)

Anais do XXIX Simpósio Brasileiro de Informática na Educação (SBIE 2018)

Etapa 3: (Condições de acertos e erros) São espalhados os 27 apontadores em cada estado do mapa e programadas as condições de acordo com os requisitos 8 e 9;

Etapa 4: (Adicionar as missões) É implementado um algoritmo para sortear a ordem da entrada das bandeiras nas missões de acordo com o requisito 6;

Etapa 5: (Condição de Vitória e Derrota) São incorporados contadores de pontos e de tempo, além de uma barra de combustível de acordo com o requisito 7;

Etapa 6: (Dicas) Um botão de dicas é inserido de acordo com o requisito 10, para ajudar quando o jogador estiver com dificuldades;

Etapa 7: (Menu inicial) Uma tela de menu é criada com botão para jogar;

Etapa 8: (Implementação do Guia) Um guia que serve como área para estudos é implementado de acordo com o requisito 1, é adicionado um botão para acessá-lo na tela inicial do jogo;

Etapa 9: (Outros modos) Nesta etapa são incorporadas duas fases para jogar, uma de Capitais e uma terceira de Brasões, ambas tem como base a fase 1, de bandeiras. É inserida uma tela de escolha, logo após selecionar o botão Jogar, de acordo com o requisito 5;

Etapa 10: (História incorporada) A história do piloto Phill, pré-escrita, é incorporada logo após da escolha da fase 1;

Etapa 11: (Tela de Ajuda) Uma sequência de telas de ajuda é adicionada logo após a da história;

Etapa 12: (Configurar o Jogo) A tela de configurações (Requisito 2) é adicionada, permitindo alterar níveis de dificuldade (Requisito 10), Redefinição do Jogo (Requisito 4) e sons;

Etapa 13: (Recordes) Uma tela de score é criada para mostrar os recordes em cada fase (Requisito 3) e também a melhor pontuação nos botões de escolha de fase, uma tela para que o usuário insira o nome quando o recorde for batido, existem botões na tela inicial e nas configurações para acessá-los.

\subsection{Criação dos Elementos do Jogo}

Os elementos visuais presentes no jogo são de produção própria, com algumas exceções de sons e telas de fundo, estes são disponibilizados na internet de forma livre. As ferramentas utilizadas para a criação dos elementos foram Adobe Illustrator CC 2017 e Adobe Photoshop CC 2017. 
VII Congresso Brasileiro de Informática na Educação (CBIE 2018)

Anais do XXIX Simpósio Brasileiro de Informática na Educação (SBIE 2018)

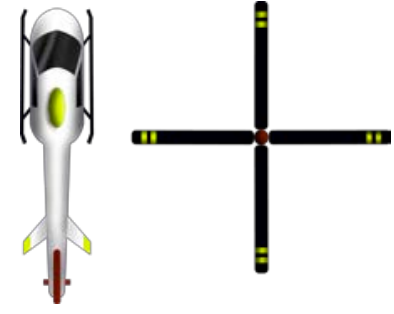

Figura 8.1 Helicóptero

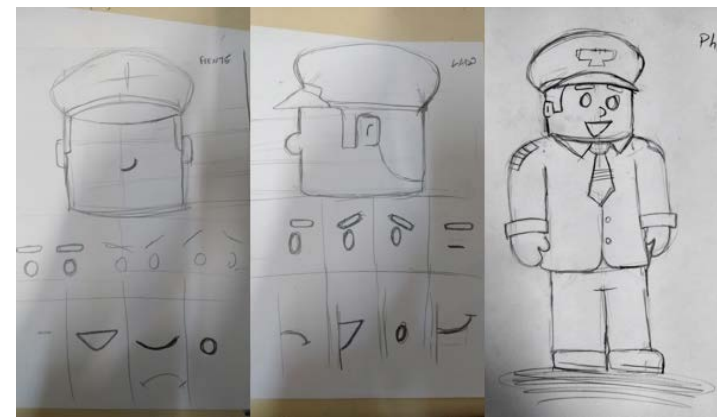

Figura 8.2 Esboços do Phill

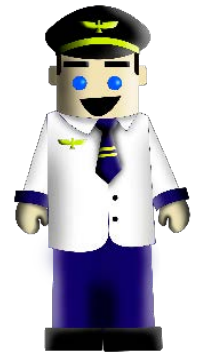

8.3 Phill

\subsection{Arquitetura do Jogo}

O Diagrama de máquina de estados para representar as transações entre as telas do jogo e os efeitos causados pelas tomadas de decisões do jogador.

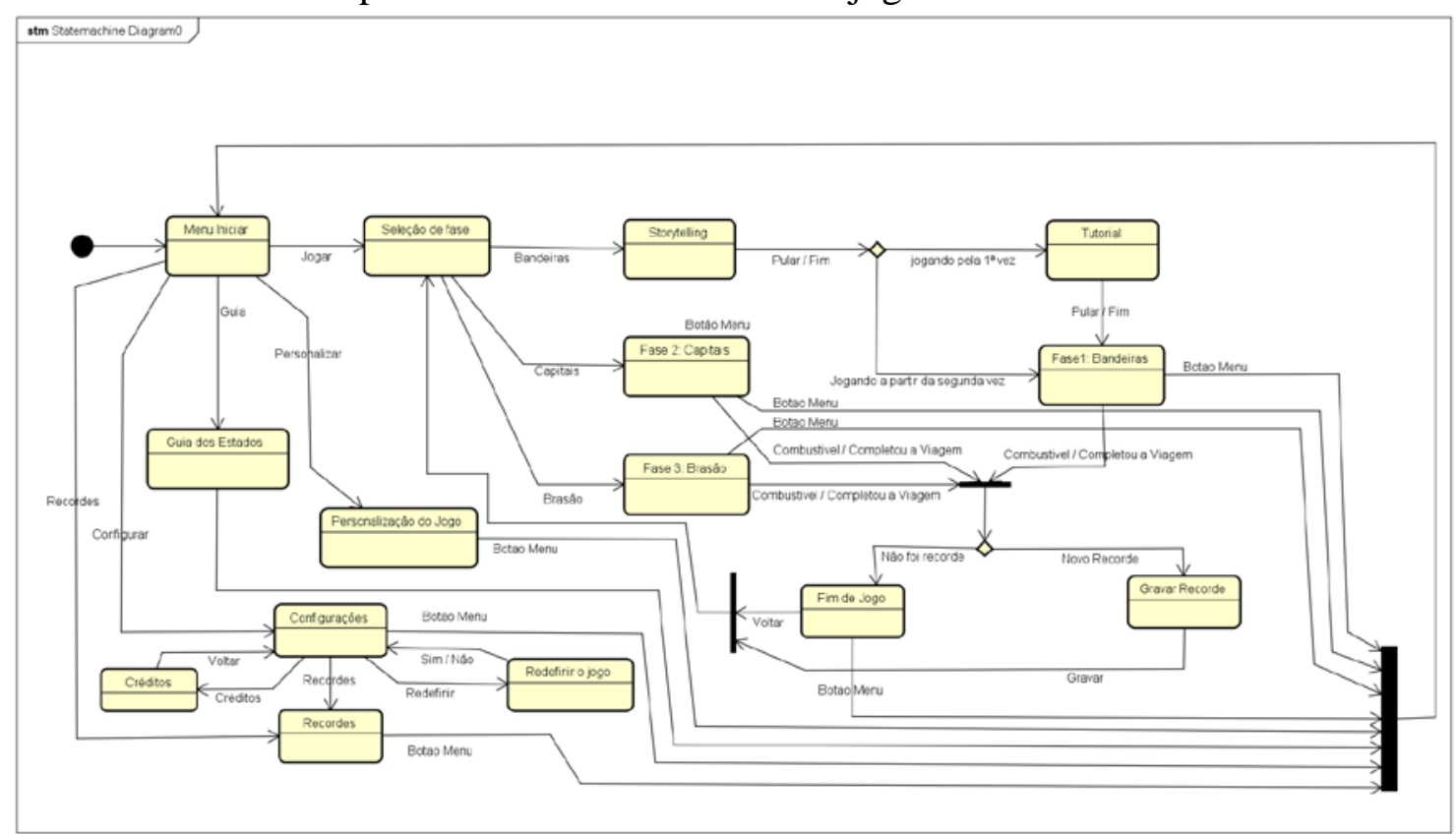

Figura 11. Diagrama de Máquina de Estados do jogo "A Viagem".

\section{Testes e discussões}

Foram aplicados testes para a avaliação da usabilidade e Gamificação com sete usuários voluntários e mais 61 instalações para qualificação do jogo na versão de teste Beta, disponível no google play. Para a etapa de testes, foi utilizado o método gameflow (Neves, de Oliveira Santos, Santana, \& Ishitani, 2014) para verificar a imersão do jogador e se os requisitos de gamificação e aprendizagem poderiam ser alcançados, além da usabilidade, foram avaliados os seguintes itens: concentração, desafio, imersão, interação social, habilidades do jogador, controle, objetivos claros e feedback.

Para a gamificação, o jogo foi enquadrado nos quesitos definidos por Alves (2015). Os quesitos estão divididos entre os elementos de dinâmica, mecânica e componentes do jogo, na tabela 1 é possível ver como os elementos estão separados e quais são os requisitos de gamificação cumpridos pelo jogo A viagem. 
VII Congresso Brasileiro de Informática na Educação (CBIE 2018)

Anais do XXIX Simpósio Brasileiro de Informática na Educação (SBIE 2018)

Tabela 1. Enquadramento de gamificação (Flora Alves).

\begin{tabular}{|c|c|c|c|}
\hline & Critério & Sim & Não \\
\hline \multirow{5}{*}{ Dinâmica } & Constrições & $\bar{X}$ & \\
\hline & Emoções & $\mathrm{X}$ & \\
\hline & Narrativa (Storytelling) & $\mathrm{X}$ & \\
\hline & Progressão & $\mathrm{X}$ & \\
\hline & Relacionamento & & $\mathrm{X}$ \\
\hline \multirow{9}{*}{ Mecânica } & Desafios & $\mathrm{X}$ & \\
\hline & Sorte & $\mathrm{X}$ & \\
\hline & Cooperação e competição & & $\mathrm{X}$ \\
\hline & Feedback & $\mathrm{X}$ & \\
\hline & Aquisição de recursos & & $\mathrm{X}$ \\
\hline & Recompensas & $\mathrm{X}$ & \\
\hline & Transações & & $\mathrm{X}$ \\
\hline & Turnos & & $\mathrm{X}$ \\
\hline & Estados de vitória & $\mathrm{X}$ & \\
\hline \multirow{14}{*}{ Componentes do jogo } & Realizações & $\mathrm{X}$ & \\
\hline & Avatares & & $\mathrm{X}$ \\
\hline & Badges & $\mathrm{X}$ & \\
\hline & Boss Fights & & $\mathrm{X}$ \\
\hline & Coleções & & $\mathrm{X}$ \\
\hline & Combate & & $\mathrm{X}$ \\
\hline & Desbloqueio de conteúdo & $\mathrm{X}$ & \\
\hline & Doar & & $\mathrm{X}$ \\
\hline & Placar ou leaderboard & $\mathrm{X}$ & \\
\hline & Níveis & $\mathrm{X}$ & \\
\hline & Pontos & $\mathrm{X}$ & \\
\hline & Investigação ou exploração & $\mathrm{X}$ & \\
\hline & Gráfico social & & $\mathrm{X}$ \\
\hline & Bens virtuais & & $\mathrm{X}$ \\
\hline
\end{tabular}

Os resultados do teste de usabilidade, gameflow, levaram em conta as notas distribuídas da seguinte forma: 0 = não se aplica, 1 = deveria ter, mas não tem, 2 = ruim, 3 = médio, 4 = bom. O teste aplicado considerou 7 princípios: concentração, desafio, habilidades do jogador, controle, objetivos, feedback e imersão. Os resultados podem ser visualizados na tabela abaixo (Tabela 2):

Tabela 2. Resultados GameFlow.

\begin{tabular}{lccccc}
\hline \multicolumn{1}{c}{ Critérios } & $\begin{array}{c}0 \text { - Não se } \\
\text { aplica }\end{array}$ & $\begin{array}{c}1 \text { - Deveria ter, mas não } \\
\text { tem }\end{array}$ & 2 - Ruim & 3 - Médio & 4 - Bom \\
\hline Concentração & $0 \%$ & $0 \%$ & $0 \%$ & $38 \%$ & $62 \%$ \\
$\begin{array}{l}\text { Desafio } \\
\text { Habilidades do }\end{array}$ & $14 \%$ & $7 \%$ & $0 \%$ & $39 \%$ & $39 \%$ \\
jogador & $2 \%$ & $4 \%$ & $2 \%$ & $33 \%$ & $59 \%$ \\
Controle & $5 \%$ & $2 \%$ & $0 \%$ & $24 \%$ & $69 \%$ \\
Objetivos & $0 \%$ & $0 \%$ & $7 \%$ & $50 \%$ & $43 \%$ \\
Feedback & $0 \%$ & $0 \%$ & $5 \%$ & $29 \%$ & $67 \%$ \\
Imersão & $18 \%$ & $4 \%$ & $4 \%$ & $43 \%$ & $32 \%$ \\
\hline
\end{tabular}

A tabela 1, demonstra que segundo o critério de análise binária, o software se enquadra nas características de Gamificação sugeridas por (Alves, 2015), ou seja, a proposta possui os elementos necessários para a promoção do engajamento pela motivação intrínseca aos jogos. A análise dos testes, aponta para resultados positivos, 
VII Congresso Brasileiro de Informática na Educação (CBIE 2018)

Anais do XXIX Simpósio Brasileiro de Informática na Educação (SBIE 2018)

como pode ser conferido na tabela 2, demonstrando que a construção de um software educacional precisa ter a preocupação com as estruturas de aprendizagem adjacentes com a finalidade de gerar aprendizagem significativa.

\section{Considerações finais}

Este artigo apresentou o software educativo A Viagem como um objeto facilitador para aprendizagem dos mapas e símbolos brasileiros, de maneira gamificada, como uma possível alternativa para a promoção conhecimento das pessoas em relação ao tema Geografia e cartografia, no que tange o mapa político do Brasil.

Como continuação deste trabalho serão aplicados testes em campo, para coletar informações para possíveis alterações, buscando melhorias que possam proporcionar uma melhor interação e conforto ao usuário. Pretende-se ainda desenvolver outras fases, separadas por continentes até perfazer o mapa mundi.

\section{Referências}

Alves, F. (2015). Gamification: Como criar experiências de aprendizagem engajadoras: DVS Editora.

dos Santos, R. d. C. E., \& Chiapetti, R. J. N. (2011). Uma investigação sobre o uso das diversas linguagens no ensino de Geografia: uma interface teoria e prática. Geografia Ensino \& Pesquisa, 15(3), 167-184.

Heller, E. (2013). A Psicologia das Cores: Como as cores transmitem a razão.

Lefrançois, G. R., Magyar, V., \& Lomonaco, J. F. B. (2009). Teorias da aprendizagem: o que a velha senhora disse: Cengage Learning.

Lemos, W., Junior, I., \& Campos Filho, A. (2017). Uma Proposta de um Serious Game no Auxílio do Aprendizado da Anatomia Humana. Paper presented at the Brazilian Symposium on Computers in Education (Simpósio Brasileiro de Informática na Educação-SBIE).

LUNKES, R. P., \& Martins, G. ALFABETIZAÇÃO CARTOGRÁFICA: UM DESAFIO PARA O ENSINO DE GEOGRAFIA. Origem não identificada.

Mayer, R. E. (2002). Multimedia learning Psychology of learning and motivation (Vol. 41, pp. 85-139): Elsevier.

Netto, D., da Silva, G., de Melo, H., \& da Costa, V. (2016). Geography History: Um aplicativo para auxílio ao ensino de Geografia. Paper presented at the Brazilian Symposium on Computers in Education (Simpósio Brasileiro de Informática na Educação-SBIE).

Neves, D. E., de Oliveira Santos, L. G. N., Santana, R. C., \& Ishitani, L. (2014). Avaliação de jogos sérios casuais usando o método GameFlow. Revista Brasileira de Computação Aplicada, 6(1), 45-59.

Oliveira, A. R. (2008). Geografia e Cartografia escolar: o que sabem e como ensinam professoras das séries iniciais do Ensino Fundamental? Educação e Pesquisa, 34(3), 481-494.

Piaget, J., \& Duckworth, E. (1970). Genetic epistemology. American Behavioral Scientist, 13(3), 459-480.

Sousa, T., Nunes, M. M., \& Martinhago, A. (2017). Universo do saber: um Jogo Mobile para Auxiliar o Ensino/Aprendizagem no Ensino Fundamental. Paper presented at the Brazilian Symposium on Computers in Education (Simpósio Brasileiro de Informática na Educação-SBIE). 